\title{
La química y la lengua del siglo XIX: nota a propósito de pajuela, fósforo, mixto y cerilla
}

\author{
Juan Gutiérrez Cuadrado \\ Universitat de Barcelona
}

0. La falta de un Diccionario Histórico como Dios manda y la proximidad aparente del siglo diecinueve desfiguran muchas veces la historia más cercana de algunas voces del español. El DCECH argumenta ejemplarmente muchas etimologías prerromanas, pero nos deja poco satisfechos si leemos las entradas de requeté o suripanta, por ejemplo. Es evidente que en este caso ni don Joan Coromines ni don José Antonio Pascual son los responsables de la desazón que nos causa el gusanillo de nuestra conciencia intelectual cuando nos susurra al oído: "No hagáis caso de explicaciones ad hoc". Estos autores, como otros muchos, son las víctimas inocentes de la idea implícita en nuestro ámbito universitario de que el siglo diecinueve está tan cerca de nosotros que lo conocemos perfectamente; padecen, como todos, las consecuencias de una cierta inercia que nos ha impedido hacer un esfuerzo filológico de cara al siglo pasado, más alejado de nosotros de lo que imaginamos. El DCECH nos devuelve, como un espejo de aumento, los propios límites que nosotros nos hemos trazado. Sólo los superaremos si nos preocupamos de la recogida, acumulación e interpretación de textos originales, lejos de cualquier tentación especulativa. Como muestra mínima de lo que señalo, me gustaría llamar la atención sobre las siguientes entradas del DRAE1992, repletas de problemas:

cerilla Varilla fina de cera, madera, cartón, etc., con una cabeza de fósforo que se enciende al frotarla con una superficie adecuada.

mixto Cerilla, fósforo.

fósforo Trozo de cerilla, madera o cartón con cabeza de fósforo y un cuerpo oxidante, que sirve para encender fuego.

1 Este trabajo se ha elaborado con la subvención de la DGICYT PB94-0918, Vocabulario de la química en el siglo XIX.

Juan Gutiérrez Cuadrado, "La química y la lengua del siglo XIX: nota a propósito de pajuela, fósforo, mixto y cerilla", 
pajuela Paja de centeno, tira de cañaheja o torcida de algodón, cubierta de azufre y que arrimada a una brasa arde con llama.

Las definiciones académicas obscurecen la relación actual entre estos cuatro términos. La sinonimia evidente de los tres primeros se pierde por la fidelidad de la Real Academia a las ediciones anteriores de su Diccionario. En efecto, los tres términos indicados con sinónimos, pero una marcación adecuada debería señalar que cerilla y fósforo son los más extendidos; que mixto predomina, quizá, en el oriente peninsular; que pajuela es actualmente una voz desusada. Aunque es verdad que cualquiera podría usar hoy una pajuela de centeno o una tira de cañaheja azufradas para encender fuego, sería extraño que pudiera encontrarse tal artículo en un comercio. Por otro lado, habría que contar también con la acepción un poco diferenciada de fósforo en ciertas zonas peninsulares ('una especie de cerilla que usaban los niños para jugar'). Parece también útil observar que cerilla funciona como término no marcado y, en cierta medida, como hiperónimo de todo el grupo. Por fin, para acabar con este comentario inicial, que podría extenderse con facilidad, no conviene pasar por alto que el DRAE-92 utiliza cerilla entre los definidores de fósforo, pero, en este caso, la acepción del definidor está claramente desusada y puede inducir a confusión el hecho de que la misma forma tenga otra acepción sinónima de fósforo.

El grupo de definiciones examinado refleja un estado de lengua del siglo $X I X$, en el que se recoge de una manera imperfecta todavía la información enciclopédica de la química. En efecto, la ciencia química desde principios del siglo diecinueve progresó portentosamente y, con ella, la industria se desarrolló de una manera extraordinaria. Algunos comportamientos cotidianos tradicionales de las gentes cambiaron con los productos derivados de las fábricas. Entre estos últimos no ocupa el último lugar el destinado a producir el fuego químicamente. Lo que merece la pena comentar no es que aparezcan objetos nuevos o que se arrinconen los desusados, sino cómo el proceso real de generalización de los nuevos objetos y el arrinconamiento de los viejos no va acompañado de un proceso paralelo en el léxico de la lengua y cómo, por otra parte, parecidos procesos reales en francés y español no tienen soluciones lingüísticas idénticas en lenguas tan cercanas.

1. En el Siglo de Oro disponemos de suficientes obras lexicográficas que nos muestran el léxico referido a las dos formas principales de obtener el fuego: a) en casa, aprovechando una brasa cualquiera con la pajuela o alguaquida (voz propia del Reino de Toledo); b) en cualquier situación con el eslabón y el pedernal, haciendo saltar una chispa sobre la yesca. Entre los numerosos ejemplos que podrían aducirse me contento con el muy conocido de COVARRUBIAS: 
sulconete. Antonio de Nebrija da este nombre a lo que comúnmente llamamos alguaquidas, latine sulfuratum.

alcrevite. Los palillos hechos de cañahejas o cañas partidas o del cáñamo, que en valenciano se llaman palletes, mojadas en alcrevite sirven para encender la lumbre, como aya alguna centella o rescoldo en que pueda prender; y éstas llaman en el Reyno de Toledo alguaquidas.

alguaquida. La pajuela mojada en alcrevite para con facilidad encender lumbre, aunque sea prendiendo en qualquier centella de rescoldo [...]. El uso de andar vendiendo por las calles las alguaquidas o palletas, y darlas por çapatos viejos y vidrio quebrado, como oy día se usa en Valencia, es tan antiguo que haze dello mención Marcial [...]. En Valencia hazen estas pajuelas de las cañuelas secas del cáñamo; y en el Reyno de Toledo de cañahejas partidas en rajuelas menudas y atadas por cientos.

[Paja]. Pajuelas, suele sinificar lo mismo que alguaquidas, por poner el alcrevite en los cabos dellas; y assí los valencianos las llaman pallets.

En el Tesoro Lexicográfico de GILI GaYA se encuentra también bastante información de los lexicógrafos del momento, franceses, ingleses e italianos: alguaquida, se traduce respectivamente por allumette; match of brimstone o zulfanello. AYALA (1693) ya advierte que es como "pajuela de encender" y que es "voz que aún usan en Toledo". Cerilla, según Ayala (1693) es "una velita muy delgada que sirve para encender las luzes en la iglesia...". SOBRINO (1705) traduce la voz como "de la bougie". Eslabón de pedernal aparece desde NEBRIJA con la acepción general del instrumento usado para hacer fuego con el pedernal. En el Tesoro pueden comprobarse las traducciones: italiano, focile, fucile; francés, fer de fusil.

AUTORIDADES refleja perfectamente la situación tradicional y coincide con Ayala en la apreciación de alguaquida. Además muestra la situación de mixto y phosphoro, anterior al siglo XIX:

alguaquida Paja o cuerda cubierta de azufre que comúnmente se llama pajuela. Esta voz se conserva oy casi enteramente en Toledo, donde llaman alguaquía a la pajuela de azufre.

cerilla Candela o vela mui delgada y larga que solo tiene mezclados con cera los pocos hilos del pábilo y cubiertos de ella con una capa o baño sutil. Sirve para encerar los cortes de las telas de seda, porque no se deshilen, passándola encendida por ellos ligeramente, y también de luz manual para alumbrarse, y de otros usos. 
eslabón Se llama también al hierro con parte de acero, con que se saca fuego de un pedernal, y de ordinario sirve para encender la yesca, y después con ella la luz.

mixto Usado como substantivo vale el compuesto de diversos elementos y se llama assí a distinción de los mismos elementos.

pajuela Significa también un pedazo delgado de cañaheja o cuerda, mojado en alcrebite o azufre, que se usa en las casas para encender prontamente luz.

phósphoro Llaman los filósofos cierta piedra mineral, cuerpo metálico u composición artificial seca o líquida que de noche luce y alumbra, de suerte que a su luz se puede leer o escribir.

La información académica no es sustancialmente diferente de la que proporciona TERREROS en esta ocasión:

alguaquida, voz sin uso, pajuela.

cerilla Fr. Bougie filée es un hilado de cera.

eslabón, hierro acerado, para sacar lumbre del pedernal. Fr. fusil; [...] it. focile.

fósforo, materia que quema, o se hace luminosa, sin que sea necesario aplicarle otro fuego[...]

mixto, cuerpo mixto, compuesto de varios elementos.

pajuela, pedazo de cuerda, o cosa semejante, compuesta con azufre para encender luz. Fr. allumette; lat. sulphuratum[...] it. zolfanello.

Estos testimonios y otros muchos que podrían aportarse demuestran que los instrumentos tradicionales que se utilizaban para encender el fuego recibían en español las denominaciones de pajuela o de eslabón y pedernal, si prescindimos de los dialectalismos. La cerilla servía para transportar el fuego encendido. En francés la pajuela tenía su equivalente en la allumette, la ceriIla en la bougie (vela) y el eslabón en el fusil, voz substituida a principios del siglo XVIII por briquet, ya que fusil, en principio un eslabón de acero que se utilizaba en el mecanismo de encendido de las armas de fuego se especializó como 'cierta clase de arma de fuego'.

2. La industria química, a principios del siglo XIX, aprovechó enseguida los usos del fósforo y del clorato potásico y fabricó instrumentos más prácticos y sencillos que los tradicionales para encender el fuego, aunque no exentos de peligro en un primer momento. En Francia, país en el que las pruebas y los ensayos menudean, se ponen de moda diferentes nombres que no han 
calado en castellano, quizá porque el ritmo de comercialización de los nuevos productos era tan rápido que algunos resultaron tan efímeros que no debieron llegar masivamente al mercado español. En cambio, se impusieron otros productos muy consolidados, que se empezaron a fabricar en la Península, y con ellos, sus nombres respectivos.

F. CARBONELL, ilustre químico catalán, es el único autor que conozco que utilizara en su traducción del manual de GIRARDIN términos para el francés briquet que no arraigaron en español. En efecto, podemos leer en la traducción española de este texto que entre las aplicaciones del fósforo, los eslabones fosfóricos son muy importantes:

El fósforo tiene muchas aplicaciones útiles, como se va a manifestar. Los químicos lo emplean a menudo para analizar el aire. Los médicos lo ordenan algunas veces como estimulante del sistema nervioso.. Su uso más común es para la fabricación de los eslabones fosfóricos. Estos se preparan tomando un tubo de vidrio o de plomo, llenándolo hasta la mitad de fósforo e inflamándole con una varita de hierro candente, y dejándo arder y ajitándolo hasta que se apaga. Durante esta operación queda en la botella o tubo un óxido de fósforo, y ácido fosfórico, mezclados con otra cantidad de fósforo no oxidado. Cuando se introduce una pajuela azufrada dentro del eslabón arriba dicho, la combustión de la pajuela se verifica al mismo instante, por la combustión del fósforo, que el frote de la pajuela determina. Cuando la pajuela no se enciende de repente, bastará frotarla sobre un pedazo de filtro o sobre un corcho. Dividiendo el fósforo con la interposición de un cuerpo inerte, como arena, vidrio molido o magnesia, se obtienen eslabones mucho más inflamables, que se venden en el comercio con el nombre de Mástil inflamable. Los eslabornes fosfóricos, puestos en uso de 15 años a esta parte, son muy cómodos, pero algo peligrosos, porque sacando vivamente la pajuela del interior del eslabón, se arrastran a menudo pequeños pedazos de fósforo, que fácilmente pueden quemar las manos o los objetos sobre los cuales caen, como lo demuestran los varios incendios causados por el uso de estos eslabones (1841, 176-77).

El texto de CARBONell nos proporciona, además, otras noticias interesantes: teniendo en cuenta que el original de GIRARDIN es de 1838, parece que la aparición en París de los eslabones fosfóricos se remonta más o menos a 1823. Es probable que algunos comerciantes, viajeros o desterrados españoles volvieran con semejante curiosidad en su equipaje. Pero, de todos modos, lo que parece cierto es que lo que en francés se llamaba briquet phosphorique, porque se basaba en el esquema del eslabón y el pedernal (de la concurrencia de dos objetos diferenciados nacía el fuego), tal como muestra con claridad la descripción de CARBONELL, no tenía denominación en español. CAR- 
BONELL calca la francesa. Aunque se refiere a pajuela azufrada, la diferencia con la tradicional es evidente: no necesita ya la nueva pajuela el calor de la brasa, como antaño, sino que es suficiente con introducirla en el botellín que contiene la nueva substancia química: la pajuela se inflama con facilidad y produce fuego, además fácilmente transportable. Traduce el químico catalán hasta el nombre comercial de la marca francesa, que en castellano resulta una denominación absurda: mástil inflamable. El mismo CARBONELL en su traducción adapta también otros términos franceses. Comenta a propósito del clorato de potasa que se usa para fabricar mezclas que se llaman "pólvoras fulminantes por el choque" (1841, 327) y que con sal, resina, azufre o serrín de madera se enciende con crepitación o sin ella de repente por el contacto con el ácido sulfúrico:

Desde que fue conocida esta curiosa reacción -prosigue CARBONELL-, no se tardó en aprovecharla para la producción de eslabones, que los llamaron eslabones oxigenados, verdaderamente ha sido una de las aplicaciones más ingenosas y más lucrativas que se han sacado de los conocimientos químicos para nuestras necesidades diarias. Al principio se preparaban los eslabones, pegando a la extremidad azufrada de pequeñas pajuelas, una mezcla de 30 partes de clorato de potasa, 10 de azufre y 8 de licopodio, reducido todo a pasta blanda con una ligera disolución de goma arábiga, colorándola de rojo o azul con un poco de cinabrio o añil. Sumergiendo estas pajuelas dentro del ácido sulfúrico concentrado, este determina la inflamación de la mezcla fulminante pegada a la pajuela, de suerte que inmediatamnete queda encendida $(1841,327)$.

En este pasaje, el procedimiento de los dos cuerpos del eslabón sigue siendo el mismo, pero la substancia fundamental de la pajuela es el clorato de potasa. Los eslabones son oxigenados. Un paso más en la modernización del encendedor es la jubilación de la botellita de ácido sulfúrico. Así aparecen los ingleses lucifers (según WEUDEL, 'friction match'):

Pero después de algunos años se han substituido a las pequeñas botellitas de ácido sulfúrico que presentaban algunos inconvenientes, los naipes cubiertos de arena fina, entre los que se comprimen ligeramente las pajuelas, y sacándolas vivamente de entre los naipes, se encienden por el efecto del calor desprendido por el frote. La mezcla fulminante que contienen las pajuelas se hace más inflamable añadiéndole un poco de fósforo. Estos nuevos eslabones llamados lucifers han sido descubiertos por un inglés llamado WATT $(1841,327)$.

El texto refiere después una escena típica, francesa sin duda, quizá parisina, porque GIRARDIN comenta el peligro de las fábricas de eslabones y narra el desgraciado accidente de una empresa de París: 
Hoy día pasean nuestras calles expendedores ambulantes que venden pajuelas químicas por el frote, compuestas como las anteriores, y que con sólo frotar vivamente contra la arena, que pegada cubre el fondo o el sobre de la caja que las contiene se encienden de repente. La preparación de las pajuelas oxigenadas o químicas es muy peligrosa, sobre todo cuando en las fábricas se trabajan a la vez muchos quilógramos de substancia[...]. Para disminuir estos fatales accidentes los fabricantes de eslabones habían disminuido las proporciones del clorato de potasa y las reemplazaban en parte con el nitro, pero como se ha introducido después en la nueva mezcla cierta cantidad muy dividida de fósdoro, las explosiones son aun más formidables, por consiguiente, nunca se tomarán demasiadas precauciones cuando se trate de unir estas substancias tan combustibles, que componen la mezcla fulminante $(1841,328)$.

Una observación económica: El clorato de potasa es caro y "la fabricación de eslabones oxigenados consume una grande cantidad" $(1841,329)$.

La traducción de CARBONELL muestra claramente cómo la denominación tradicional, pajuela, con un modificador genérico (química) o más específico (oxigenada, fosfórica) se adopta para un objeto nuevo, aunque con una función parecida al antiguo: producir el fuego. En este contexto, tanto eslabón, en sus diferentes modalidades, como pajuela, son traducciones del texto francés. En efecto, los franceses siguen con la denominación tradicional allumette, modificada de acuerdo con la nueva realidad: chimique, oxygenée, phosphorique. Así describe HOEFNER las allumettes chimiques en su Dictionaire:

Un mélange de 100 parties de chlorate de potasse, de 12 parties de soufree et de 10 parties de charbon, s'enflamme au contact d'une baguette prèalablement trempée dans de l'acide sulfurique. C'est pour la propriet'e oxygénante du chlorate de potase qu'est fondée la théorie de la prepatation des allumettes dites chimiques. [...]. "Lorsqu'on plonge ces allumettes dans de l'acide sulfurique il y a production de flamme. [Otra pasta que no exige ácido sulfúrico y se enciende al frotar está compuesta de clorato de potasa, sulfuro de antimonio, fósforo, peróxido de manganeso y agua. Si se usa nitro en vez de clorato de potasa, basta frotar y se enciende sin ruido la allumette] $(1846,25)$.

En el Trésor se documentan allumettes chimiques, oxygénées, phosphoriques, suedoise, de sûreté. Esto es lo que BoullLet (1877) s.v. allumette también especifica: las allumettes tradicionales soufrées han sido sustituidas por las chimiques, entre las que se distinguen las oxygenées (con clorato de potasio), que necesitan de un frasco donde se mojan para que se inflamen; las phosphoriques, que se inflaman por frotamiento; las hygiéniques de sûreté; las allumettes bougies, etc. Entre los briquets, distingue -s.v. briquet- el tradicional (ordinaire); el chimique (allumettes oxygenées o phosphoriques); el de gaz 
hydrogène; el oxygéné (y remite a clorato de potasio). En francés, por tanto, continúa la denominación tradicional de los instrumentos para encender: el eslabón (briquet) es químico y no choca con el pedernal, pero sigue teniendo la función de producir fuego, es un encendedor o un mechero. Por ello, SALVAT (1876) s.v. briquet, introduce boîte à briquet, 'avíos de encender' y actualmente (HACHETTE, PETIT ROBERT) se usa briquet como 'encendedor' (briquet à quartz, à gaz, à essence, de table, etc.). Esta situación es bien diferente de la que CARBONELL expone en una nota añadida al explicar cómo se fabrican los nuevos encendedores:

Otra de las aplicaciones muy útiles que se han hecho del fósforo es la preparación de los mixtos, que tan en uso se han puesto por su comodidad y baratura. Para prepararlos se practica el método siguiente: En un pequeño vaso de plata con su corrrespondiente mango, se disuelven a un calor lento la sexta parte de una onza de goma arábiga con la tercera parte de otra onza de agua destilada; luego se le añade la vigésima parte de onza de licopodio, la duodécima de vermellón, media onza de salitre refinado, y finalmente la sexta parte de una onza de fósforo cortado en pedacitos los más pequeños que posible sea, cuidando de menearlo con una barita de vidiro hasta la perfecta mixtión de dichas substancias, manteniendo el vaso a un calor lento hasta que la mezcla siendo de consistencia espesa, después de fría quede en estado sólido. En este estado se separa del fuego y se coloca una pequeña parte al extremo de una tirita de cartón cortado en pedacitos, unidos por sus extremos, cuyo cartón está de antemano preparado y embebido en una disolución de nitro refinado disuelto en agua, o empapado en un barniz craso. Cuando sólo tiene la disolución del nitro, con el simple roce arde la mezcla fosfórica del extremo y continua la combustión sin llamas mientras dura el cartón; y cuando tiene barniz arde con llama hasta al fin del cartón. También se preparan unas cerillas muy delgadas, colocando al extremo una corta porción de la mezcla fosfórica; y frotando ésta, queda encendida la cerilla $(1841,467)$.

Esta nota es muy interesante. En primer lugar, sin la presión por reflejar fielmente el original francés, el traductor utiliza espontáneamente mixto, probable catalanismo del castellano, o al menos orientalismo peninsular, en esta acepción. En segundo lugar, alude ya a la acepción moderna de cerilla. Teniendo en cuenta que CARBONELL es catalán, se confirma la apreciación de J. COROMInes en su Diccionari Complementari:

pron. vulgarment mistos, el plural fou usat des de princ. S. XIX per designar la tigeta combustible amb mixtura inflamable, objecte que no ha tingut en català autèntic altre nom que aquest o el castellanisme cerilla, 
mentre que mistos no es castellanisme, encara que a base del plural mes usat, se n'hagi tret un singular misto.

En ningún otro autor de la primera mitad del siglo XIX he encontrado una información tan completa sobre los nuevos encendedores. Un poco más tarde, ORIOL RONQUillo (1851) comenta en su diccionario a propósito de fósforo:

Los señores Castanys y Degollada [...] acaban de realizar la fabricación del fósforo, sin arredrarse por lo árduo de la empresa[...]. Los usos del fósforo son limitados; sin embargo, de algunos años acá la fabricación de pajuelas consume gran cantidad de esta sustancia[...]. El consumo de fósforo en España para cerillas y cartones se calcula en 90.000 libras anuales.

Verdú, traductor de ReGnaUlt $(1851,166)$ también se refiere a "pajuela o cerilla". La Revista Farmacéutica $(1860,62)$ se refería a "fósforos de seguridad: en madera, cera, yesca, papel, etc. que sólo se encienden frotándolos sobre un cuerpo especial". MUÑOZ DE LUNA, por fin, en su manual tan difundido observaba:

La producción del fósforo es considerable en los centros industriales; sólo Francia fabrica sobre cinco mil arrobas al año. En España hay también algunas fábricas de fósforo; habiendo llegado a tal perfección y baratura la elaboración de los fósforos ordinarios, que con verdad podemos decir que hoy día excede nuestro país a todos respecto de este artículo: lástima que el clorato de potasa que agregan a la pasta, y es causa de la proyección del fósforo inflamado, con riesgo del consumidor, no se destierre del todo de la fabricación. También sería de desear que en los fósforos finos llegáramos a competir con los que se fabrican en Francia e Inglaterra. Por lo demás, he aquí una de tantas fórmulas como pueden darse para la confección de la pasta de fósforo destinada a la preparación, por ejemplo, de cerillas[...]. La pasta con la que hacen los franceses los fósforos finos, inflamables sin detonación, es la siguiente $(1864,1,392)$.

3. Esta situación, bastante clara ya en 1864, se refleja de otra manera en los diccionarios:

El DRAE-52 documenta en las acepciones que nos importan ahora:

cerilla: Vela muy delgada y larga que se enrosca en varias figuras y más comúnmente en la de librillo. 
fósforo: La pajuela fosfórica de cerilla o cartón para encender luz. mixto: [no se incluye la acepción].

pajuela: Pedazo delgado de cañaheja, cuerda, etc., mojada en alcrebite o azufre, que se usa en las casas para encender prontamente luz.

El DRAE-1884 mantiene la situación del de 1852, con una diferencia: la definición de cerilla se completa con la observación "sirve para luz manual y para otros usos". Si repasamos otros diccionarios del siglo XIX concluiremos que todos los examinados coinciden en lo fundamental con el DRAE-1852 y 1884 en las acepciones que aquí interesan de cerilla y pajuela, como muestran De la VeGa, 1845; Joaquín Domínguez, 1848-49; Do Canto e Castro, 1864-66; Marty Caballero, 1870; De Ramón, $1886-89$ y el Grupo de Literatos, 1891. La acepción de fósforo que nos interesa también está presente en casi todos, con pequeñas diferencias: "Cada una de las pequeñas porciones que en la punta de una cerilla, cartón etc., sirven en el uso común" (DE LA VEGA, 1845). "Pedacito de cartón, cerilla, yesca o cualquier otra sustancia análoga en cuya extremidad se pone una especie de pasta en cuya composición entra el fósforo en una parte proporcionada para producir fuego por nedio del roce o de la percusión y poderse encender en él cigarros, mechas velas, etc. La Acad. no vende fósforos" (JOAQUín DOMínGuez, 1848-49; parecida definición en Marty Caballero, 1870). "Preparado que se usa para accender lume, etc." (Do CANTO E CASTRO, 1864-66). "(Arte y ofic). Se da este nombre a unos pedacitos de cartón, de cerilla o de otra substancia impregnados por unos de sus lados de una composición en la cual entra el fósforo y que se enciende por fricción" (De RaMón, 1886-89). La acepción de mixto que nos interesa no se documenta, pero sí otra que la explica: "todo cuerpo sólido y compuesto que sea inflamable por el roce o por el contacto del aire" (JOAQUín DOMínGUEZ, 1848-49). Misto: "composto de substancias inflammaveis de que se usa na guerra" (Do CANTO E CASTRO, 1864-66). "Composición hecha de varios simples inflamables, llámase también mixto incendiario" (GRUPO DE LITERATOS, 1891). La acepción actual de mixto, con definición sinonímica, aparece por primera vez en el diccionario de MARTY CABALlero, 1870: "cuerpo inflamable por el roce o percusión- fósforo".

4. Si resumimos lo que nos muestran los textos químicos y los diccionarios, podemos llegar a algunas mínimas conclusiones:

a) Tradicionalmente las pajuelas con la punta azufrada (francés, allumette), que se inflamaban al rescoldo, servían para encender el fuego casero. Otras veces se echaba mano del eslabón (francés, briquet) y el pedernal para encender lumbre. Esta solía trasladarse y conservarse con las velas muy finas, las cerillas (francés, bougies). 
b) La substitución de los elementos tradicionales por otros modernos, no modificó en francés la terminología tradicional: allumette y briquet continuaron usándose, con especificaciones diversas: chimique, phosphorique, oxygénée, etc[...]

c) A pesar de que los textos químicos españoles dependían de los franceses, la traducción circunstancial del francés briquet por su tradicional denominación española eslabón, no triunfó, (fueran los eslabones químicos, oxigenados o fosfóricos). Habrá que estudiar, sin duda, lo sucedido con encendedor y mechero en español, pero no tengo intención de ocuparme de ello ahora.

d) La tradicional equivalencia entre allumette y pajuela llevó a los traductores a servirse de la denominación española pajuela (CARBONELL, VERDú, ORIOL RONQUILLO). Sin embargo, pronto pajuela sufrió la competencia de mixto, fósforo y cerilla.

e) En español se prefierió para la nueva realidad nuevas denominaciones: el abandono de eslabón fue paralelo al abandono de pajue$l a$, al contrario de lo que sucedió en francés.

f) Las nuevas denominaciones partieron de las nuevas realidades. Por metonimia se empezaron a llamar los nuevos encendedores como la substancia que se ponía en el extremo del cartón o de la cerilla: fósforos. Parecido esquema produjo la denominación mixto, porque efectivamente era una mezcla la que se ponía en los extremos de los cartoncitos o cerillas. Como ya he comentado, mixto parece propio del oriente peninsular. Aunque cerilla denominaba ya a un objeto tradicional, la generalización de la nueva acepción se produce también por metonimia, porque con fósforo se untaban o cartoncitos o cerillas. Las pajuelas se perdieron, entre otras cosas, porque no se empleaban en la fabricación de estos encendedores.

g) Si se quisieran hacer consideraciones sobre los prototipos o los estereotipos, habría que comentar que en este caso en español triunfó la consideración concreta de la materia del objeto y en francés su uso funcional.

h) En los diccionarios españoles del siglo XIX no aparece la acepción de mixto que estamos comentando, excepto en MARTY CABALLERO. Se mantiene la acepción de pajuela, aunque en los textos químicos parece preferirse fósforo o cerilla y no se recoge todavía la 
nueva acepción de ésta última voz. Tampoco se documentan las lexías fósforo de seguridad o fósforo fino.

En resumen, los textos especializados aportan información importante para reconstruir la configuración del léxico de un campo determinado, léxico que no puede sólo conocerse a través de los diccionarios.

\section{BIBLIOGRAFÍA}

Autoridades: ReAl ACAdemia Española (1726-42): Diccionario de la lengua casteIlana, Madrid, (Edición facsímil, Madrid, Gredos, 1963, 3 vols.).

BOUILLET, M. N. (1877): Dictionnaire universel des sciences des lettres et des artes, Paris, Hachette, $12^{\mathrm{a}}$.

CNRS, Trésor de la langue française, Paris, Gallimard, 1971-94 (16 vols., el 1ำ dirigido por P. Imbs)

DCECH: COROMINAS, J., PASCUAL, J. A. (1980-91): Diccionario crítico etimológico castellano e hispánico, Madrid, Gredos, 6 vols.

COROMINES, J. (1980-87): Diccionari etimològic i complementari de la llengua catalana, Barcelona, Curial-La Caixa.

CovarRubias, F. (1611): Tesoro de la lengua castellana o española, Madrid, J. Sánchez. (Edición facsimilar de M. de Riquer, Alta Fulla, Barcelona, 1943).

DE LA VEGA, P. (1845): Diccionario popular de la lengua castellana, Madrid.

DE RAMÓN, L. P. (1886-9): Diccionario popular universal de la lengua española Barcelona, 6 vols.

do Canto e Castro Mascarenhas Valdez, M. (1864-66): Diccionario españolportugués, Lisboa, Imprenta Nacional, 3 vols.

DRAE-1852: ACADEMIA EsPAÑola (1852): Diccionario de la lengua castellana, Madrid.

DRAE-1884: ReAl Academia Española (1884): Diccionario de la lengua castellana, Madrid.

DRAE-1992: ReAl ACADEMIA Española (1992): Diccionario de la lengua española, Madrid.

GILI GAYA, S. (1960): Tesoro Lexicográfico (1492-1726), I, (A-E), Madrid, CSIC. GIRARDIN, J. (1841): Lecciones de química elemental, con figuras repartidas por el contexto, explicadas los domingos en la Escuela municipal de Ruan, (traducidas de la edición francesa de 1839 y adicionadas por F. CARBONELL $Y$ FonT), Barcelona, Imprenta de J. Matas y de Bodallés, 2 vols.

Grupo de Literatos (1891): Novísimo Diccionario de la lengua castellana, París, Garnier. 
HACHETTE, Le dictionnaire de notre temps, P.aris, 1991.

HoEfer, F. (1846): Dictionnaire de Chimie et Physique, Paris, Librairie Firmein Didot Frères.

JoAquín Domíncuez, R. (1848-9): Diccionario nacional o gran clásico de la lengua española, Madrid, E. Tipográfico Mellado, 2 vols.

MARTY CABAllero, M. (1870): Diccionario de la lengua castellana, Madrid, M. Rodriguez.

MUÑOZ DE LUNA, R. Torres (1864): Lecciones elementales de química general, Madrid, $2^{\mathrm{a}}$ ed., 2 vols.

ORIOL RoNQUILLO, J (1851): Diccionario de materia mercantil, industrial y agrícola, Barcelona, 4 vols.

PETIT ROBERT, Dictionnaire de la langue française, Paris, 1989.

ReGnault, V. (1850): Curso de Química elemental, traducido por Gregorio Verdú, capitán de ingenieros, París, Imprenta Chapelet.

Revista Farmacéutica. Suplemento a la Botica, Madrid, Bailly-Bailliere, 1860.

SAlVÁ, V. (1876): Nuevo diccionario francés-español y español francés, Paris, Garnier, 6a.

Terreros, E. (1786): Diccionario castellano con las voces de ciencias artes, Madrid, Viuda de Ibarra (Madrid, Arco Libros, facsímil, 1987, 4 vols.).

WeUDlE: Webster's Encyclopedic Unabridged Dictionary of the English Language, N.Y., Gramercy Books, 1989. 